\title{
An Experimental Study of Interactive and Cooperative English Writing Strategy under Network Environment
}

\author{
Li Wei \\ Liaoning Police Academy, Dalian, China
}

\begin{abstract}
The college English writing strategy and the students' performance in English writing are two problems puzzling the foreign language researching and teaching staff in China. The paper aims to find some effective strategies to unravel this obsession. According to the successful practice of Experiencing English Writing Platform in Tsinghua University, and based on a series of theories of the Mediated Learning Experience, the Constructivism, and the structure creation, the author proposes the interactive and cooperative writing strategy under network environment. This writing strategy revolutionizes the traditional teaching pattern mainly recurring to blackboard and teacher's unitary evaluation; it takes advantage of selfstudy platform, QQ group software, and E-mail system to realize scripless, instant and interactive writing training and evaluation. The main purpose of the strategy is, on one hand, to reduce the teachers' workload in making comment and correction, helping them focus on the writing content and process rather than language form and product; on the other hand, to promote the students' self-evaluation and mutual-evaluation system, and thus enhance their abilities in individual and critical thinking. The practice of this innovative writing strategy obtains its desired results: 80 subjects in this study improve their abilities in expressing their ideas in correct and logical way and organizing their content in rational and attracting skill; they have grown to cultivate proper and efficient English writing habits with the assistance of interaction and cooperation atmosphere. After repeated reflection and further exploration, this writing strategy is bound to be improved from different perspectives.
\end{abstract}

Index Terms - writing strategy, interaction and cooperation, VPIE platform, Growing-up QQ English Group, e-mail system

\section{INTRODUCTION}

From a macroscopic perspective, the economic globalization makes higher demands for the college students' foreign language capability, and in particular, for their oral and written English capabilities. The English writing ability is a vital indicator to measure the college students' English comprehensive ability, but English writing has always been regarded as one of the weak links for Chinese English learners. In CET 4 and CET 6, the commonly low scores in writing section is a case in point. This is partly attributable to the traditional writing pattern which is marked by its flaws of taking-time and low-efficiency. It tends to stress the writing product rather than writing process; it tends to stress the text form rather than thought expression; it tends to stress the writing techniques rather than writing contents. All these improper concentration and direction lead to inefficient and ineffective writing. Although the teachers and students have done a lot to improve the writing techniques, the results are always disappointing. In fact, writing is a rather practical course which is inseparably linked with writer's personal experiences.(Numan,2004) With the extensive application of computer and information into foreign language teaching, the network platform, the QQ software, the Email system, and the Electronic Mutual Evaluation all have come into effect on writing training. Li Zhixue (Li, 2003) points out: the trend of writing study is that learners turn to the main body of subjects, with software and network widely applying into its study.

The paper makes a tentative exploration to establish a comprehensive and effective writing teaching and training system with assistance of computer and network. It begins with the theoretical analysis and teaching review in Tsinghua University. The main theoretical underpinnings are Mediated Learning Experience, Constructivism, and Input Hypothesis, and the teaching experience focuses on resources sharing, platform training, skill developing, and team teaching. The third part is the author's main illustration about this interactive and cooperative writing strategy which includes distinctive English writing classroom, after-class multiple writing training through a couple of information systems, such as Automated Evaluation System, QQ Group software, E-mail system. In the fourth part the author analyzes the innovative points of this strategy, its affirmative results and inevitable drawbacks. To conclude is the author's expectation and recommendation for this writing strategy.

\section{THEORETICAL EXPLORATION AND PRACTICAL EXPERIENCE}




\section{A. The Mediated Learning Experience}

Reuven Feuerstein, an Israeli cognitive psychologist, applied social interaction theory into teaching area in 1991. He put forward the theory of mediated function, arguing that the teacher fulfilled the mediated functions of intention, significance and purpose. (Feuerstein, 1991) Teachers devise and adjust their teaching strategies according to learners' requirements, employing digital writing platform to realize intervening teaching by means of analyzing the efficient information feedback from platform. These strategies can promote the learners' initiative, teamwork, oral English fluency and accuracy.

\section{B. The Constructivism Theory}

This popular theory holds that the individual cognitive development is closely relevant to the learning process. Knowledge can be obtained by meaning construction with others' help and necessary learning materials under some certain context. The Constructivism, on one hand, underlines the learners' function of subjects, and the student-centered learning style; on the other hand, accentuates the authenticity and sociality in the learning process. The network environment provides the learners with a positive learning environment in which learners can exert their talents and initiative to throw themselves into writing activities. This is an interactive, open and limitless environment which facilitates individual and personalized writing process.

\section{The Theory of Structure Creation}

According to Krashen's points of view, tremendous language input leads to meaningful language transformation, which indicates the significance of adequate information input for writing course. Under the network environment, there are abundant writing resources with so many excellent writing examples for learners to analyze and imitate. Meanwhile, teachers can assign various forms of composition to train students' writing abilities, and this enhancement of information input reinforces the content-centered language activities. (He, 2007)

\section{The Successful Practice of Experiencing English Writing in Tsinghua University}

After one decade of teaching exploration and practice, Tsinghua University has paved a new way for English writing, establishing a complete set of teaching and training pattern including various writing resources and technological support. It reflects four chief characteristics: (1) Resources sharing. It establishes such digital repository as Chinese students' tremendous writings base, typical writing errors-guide base, software of elementary writing, applied writing, creative writing, and academic writing, the textbook and software of Experiencing English Writing. (2) Platform training. The complexity of English writing is especially in need of delicate platform support. The famous international journal Language Testing discussed the reliability and validity of automated evaluation system and the influences of English error-correction system on foreign language learning effects. (Xi, 2010) Many special teaching software are developed to form the platform pattern in accordance with the fresh idea. These creative softwares include Automated and Generated Abstract software, Thesis Writing Expert System, Writing Evaluation Generated software, etc. They also develop a new product of intelligent platform capable of fulfilling three tasks together: scoring, commenting, and reporting of the writing. These digital writing feedbacks all come from American writing experts' comments which not only arouse the students' desire for writing, but also enrich their language expression. (3) Skill training. Naturally speaking, English writing is the transmission of one skill. To be good at writing, you have to depend on the support of technological textbook. Tsinghua University writing pattern implements the viewpoint proposed by Larsen-Freeman that grammar learning should be developed side by side with listening, speaking, reading and writing, turning to be the $5^{\text {th }}$ skill in English learning. (Larsen-Freeman, 2003) So they emphasize the language accuracy when directing the students' writing practice, leading them to error-free writing. (4) Team teaching. The teamwork is a fundamental requirement for the sound development of academic traditions. (Murray, 1994) The experience of Tsinghua University Experiencing English Writing team proves that the development of digital English writing products is a systematic engineering combining network engineers, programmers, computer artists, foreign experts, linguists, English teachers, and students altogether. The faithful cooperation among these elites contributes to the cultivation of group consciousness, collaborative learning, good classmate relationship, and social practice.

\section{Practice of Interactive AND Cooperative Writing Strategy with Network Assistance}

\section{A. The Change of Writing Course and Direction in the Classroom: Different Tasks of Three Subjects}

The writing course is completed in the multimedia classroom, and each computer is equipped with digital writing resources including some writing evaluation system, such as WRM system, some network platform, such as Experiencing English Writing of Tsinghua University. The teacher imparts writing elements through multimedia broadcasting teaching in a specific order according to different units. For instance, the teacher employs the electronic software of New College English Integrated Course 3 to introduce different writing styles of comparison and contrast essay. After illustrating the main points of writing skills, the teacher will assign different writing tasks: My Dream Life and Real Life; Dalian and Shenzhen. 


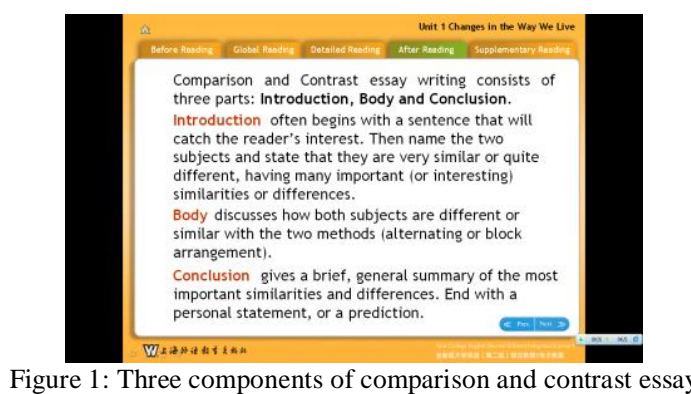

Apart from the classroom change, the procedures of writing class also change. In general, there are a series of class activities in our writing class which include teacher's tasks: theoretical illustration, writing assignment and final evaluation; group tasks: group discussion on the new theory or skill, group analysis of the new writing task, group evaluation; student's tasks: writing practice (from outline to detail), self-evaluation (one or two times), submission, feedback and reflection. Figure 2 illustrates three main tasks for three subjects in writing classroom.

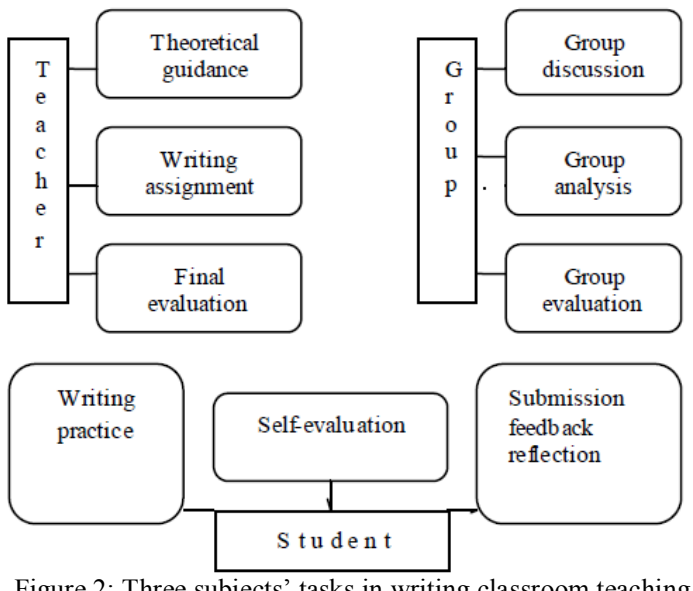

Figure 2: Three subjects' tasks in writing classroom teaching

\section{B. The New Pattern of Writing Training after Class: The Interactive Combination of Network Platform, QQ Group Software, and E-mail System}

Application of automated evaluation system: In our academy, we have established a platform entitled VPIE (Virtual Policing in English) (Wei, 2011) to train students' practical and professional English skills under virtual environment. The teacher utilizes this platform to help students' self-improvement in English writing by means of Automated Essay Scoring, such as Writing Roadmap, and other online writing editing resources, such as Google search engine, and some text processing programs, such as Wordpilot 2000, Check My Words, Word Neighbors. The automated evaluation system initiated in 1960s in America, and with the development of network and information technology, it has made profound progress in its various functions to meet requirements of teaching instruction and training evaluation. WRM is an automated system and a teaching-assisted system which possesses writing evaluation criteria in six dimensions: content, structure, voice, vocabulary, fluency, and correctness. After each writing class, the teacher will give students one or two writing assignments, and the students put their writings on WRM after self-evaluation. With assistance of WRM evaluation, the student will revise his or her composition again according to scoring in different dimensions. The practice of WRM training in six months indicates that WRM system can offer timely and effective supervision and guidance. The teachers spend less time on the correction of compositions and they can put more efforts on directing macro writing techniques and examining the state of implementation. That is to say, the emphasis of writing teaching has changed from the language forms to writing contents and expressions, from writing product to writing process. In the process of writing practice, the key link of it is to correct the composition. The timely feedback of automated evaluation system not only encourages students to correct their compositions immediately and raises possibilities of correction through evaluation feedback and resources. The teacher also gives the particular feedback according to the students' evaluation records, making up for the evaluation absence of the electronic system.

Application of $Q Q$ group software: The author established a QQ group entitled Growing-up English QQ Group (Wei, 2012) in April 2012; it carried out a series of English learning and entertaining activities. The writing training was also integrated into its regular operation. For instance, the teacher uploaded many materials in writing principles and techniques in her spare time, such as How to write a standard international paper?, see Figure 3. 


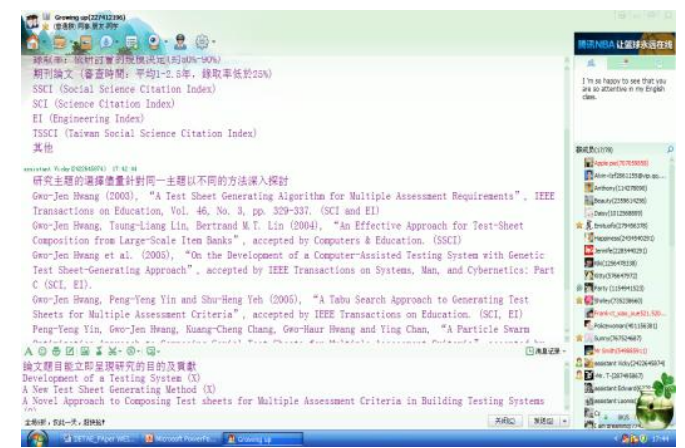

Figure 3: Teacher's illustration of international paper writing methods in Growing-up QQ group on Nov. 11 ${ }^{\text {th }}, 2012$.

The writing guidance and personal correction from English teacher via QQ group plays the significant role in students' final success in their writing course. Due to the time limitation in writing class, the teacher resorts to the cyber space to realize seamless or remote direction and supervision. For example, the author has corrected Tong Keni's (a student majoring in Investigation in Grade 2011) drafts of speech for three times in order to fulfill the requirement of less than three-minute speech and reach a higher level of provincial speech contest. Fortunately, she obtained the third prize in the contest (in October, 2012). After her own correction and author's repeated revision, this speech manuscript has attained her highest level for a college sophomore. We can appreciate this final version.

\section{Health and Happiness}

Many philosophers and thinkers have been discussing what is the most significant factor for human's whole life and they always come to the same consensus: health and happiness are two pivotal elements in building a contented and rounded life. As is known to all, Health always means much to every species, not to mention mortals. Health is reflected in all dimensions of human being, including physical, emotional, mental and spiritual well being. It is a state of higherleveled harmony between body and mind. With health, the growth and achievement will naturally follow on, for health provides us with the fundamental element to accomplish our daily routine, and the enormous driving force to realize our great ambition.

When it comes to happiness, it involves the ability to love and work. Aristotle said: happiness is the whole aim at the end of human existence. We usually define happiness as a way of life, or an attitude towards our living condition. It is an overriding outlook composed of qualities such as optimism, courage, love, and fulfillment. Once these four virtues could become indispensable part of your life, harboring positive and optimistic emotions, fulfilling responsibility and assignment heart and soul, our life would be warmer with spring sunshine, and our world would be harmonious with common dedication.

As a matter of fact, however, health and happiness are also twin sisters; they are closely connected with each other and can be interchanged accordingly. A healthy life will be full of happiness, and in turn, people who live happily will usually lead a healthy life style. But how to maintain healthy and how to pursue happiness? Human's felicity is generated not so much by great pieces of good fortune that seldom happen. So, we shouldn't be extremely depressed or despaired at the time we feel unfortunate or unhealthy. To change a different perspective, and to give ourselves a period of time to balance our mental and psychological demands. Nothing will offer you a deep sense of health and happiness, unless you cultivate them consciously and continuously. It's not something that created by outside circumstances, but, instead, it is completely within your own control. So, my friends, if you are easy to be depressed or disappointed, if you are always dissatisfied with your present life, please listen to me, to get moving and, to make better daily choices. Try not to get down when a slip-up happens. Every day is a new day, and everyday you'll have a new chance to take a step in the right direction. This is the very secret of being healthier and feeling happier than yesterday.

I do believe all sufferings have their rewards. The failures and frustrations will add dignity and courage to the prospect of human life. Since no health and happiness are at hand, do you make adequate preparation to face up to the challenge of pursuing and living a healthy and happy life?

In fact, every writing progress is indispensable to students' careful creation and teacher's elaborate evaluation with assistance of automated evaluation system. Apart from this typical speech, the author also made comments and evaluations on many other students' compositions through QQ group sharing. Xu Hong uploaded his composition to the group sharing, and the author gave open correction and evaluation to make Xu Hong and other students aware of the merits and demerits in his composition, see Figure 4. The open correction and evaluation has many advantages over the traditional evaluation system which only benefits a single subject, while the open one can benefit more group members instantly online or offline, and meanwhile, this open and instant evaluation can arouse the students' interest in writing activity and give them the clear direction in how to write correctly and logically. 


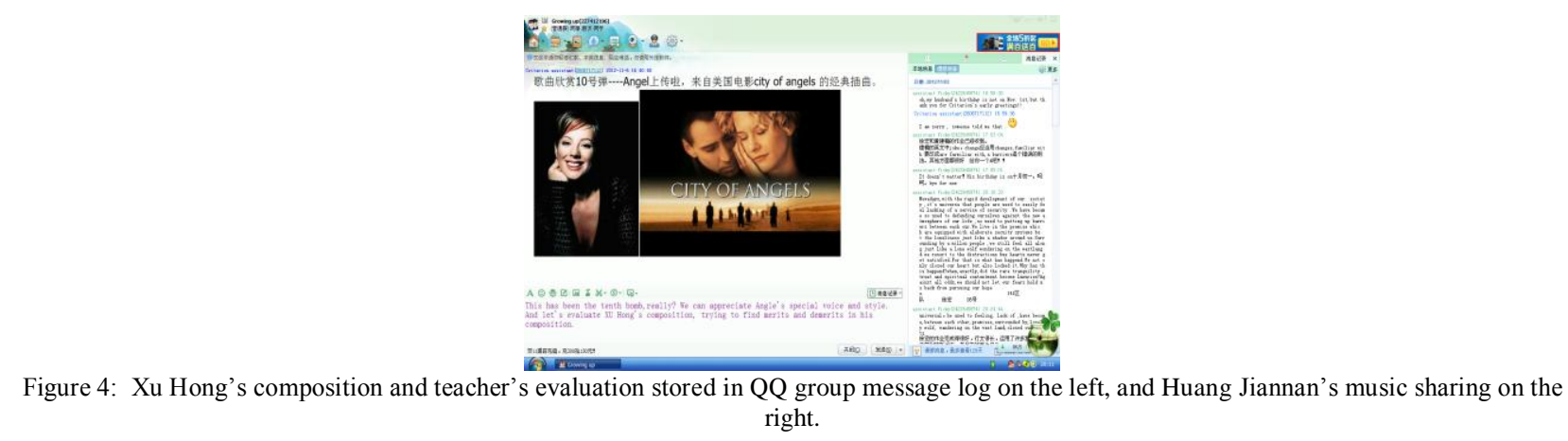

Application of E-mail system: In view of the fact that some of the students who want to make person-to-person communication and require teacher's individual assistance and correction, the E-mail evaluation system is applied to use. E-mail system is a kind of asynchronous writing practice, which is beneficial to students' comprehensive writing abilities and cooperative learning spirits. About 40 percent of students ( 80 students in all) are willing to send their writing assignments to the teacher E-mailbox. Figure 5 presents us with a student's composition through E-mailbox.

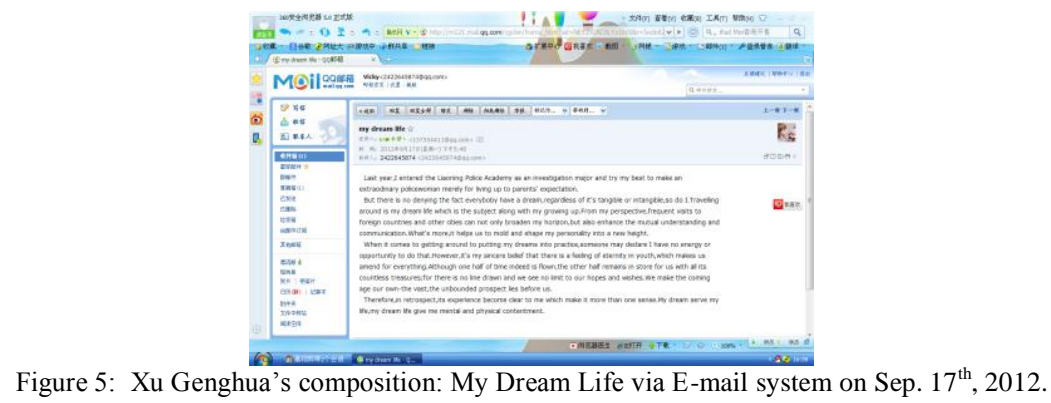

Whatever a composition is uploaded to English QQ group or sent to E-mailbox, the teacher should take them seriously and equally, giving them careful comments, pertinent suggestions, and sound evaluation in different dimensions. The students can receive the most detailed feedbacks in the shortest feedback cycle, which will inspire students' desires to write articles on their own and enhance their writing awareness, senses and skills.

\section{Analysis of Research InNOvative Points, Outcomes AND Existed Problems}

\section{A. The Innovative Points of the Reformed Writing Strategy}

Innovation in learning means: the traditional writing course is featured by blackboard, paper and face-to-face explanation. The new writing strategy, however, transplants the network technology into writing training, realizing the digitalization of learning resources. The classroom teaching environment transforms from traditional classroom to network classroom with computers hooked up to the internet. Teacher can utilize multimedia broadcasting teaching, supervising relay, remote assistance, documents hand-out to network the learning process. Teacher and students feel the intuitionistic, swift, and efficient classroom teaching owing to the introduction of computer technology into writing class. Moreover, non-paper reading, writing, and peer-review have been applied in routine training. Students write their assignments on the computer, and upload them to QQ group software to receive peer-review from other QQ group members, and e-mail the revised one to the teacher. At last, the teacher makes the open commentary on QQ group. All the writing process indicates computer-assisted training contributes to the development of students' intercommunication skills, reading and writing skills as well.

Innovation in learning methods: this study emphasizes learners' participation, personal practice, and group cooperation, advocating progressive classroom teaching and after-class cooperation and interaction. Classroom teaching is closely connected with after-class personal experience, that is to say, the teacher can undertake writing direction and give assignment in class and after class; the students can listen to teacher's guidance in and after class; writing evaluation can be fulfilled in the same way. This open and easy after-class learning environment can promote students' learning desire for after-class writing. The students can increase their writing interests and abilities by self-study on the platform or QQ group interaction with other group members. Every writing assignment is submitted after group evaluation, and this process leads to the development of cooperative learning and teamwork. The previous study of cooperative writing interaction reveals that cooperation with other classmates may trigger active and creative thinking, prompt discussion, and unravel diverge. At the same time, this writing pattern may promote mutual learning and helping each other in terms of rhetoric, structure, theme, and language use, and hence, improves learning effects. (Shi, 2004) 


\section{B. The Affirmative Research Outcomes}

Based on the innovative writing pattern with network support featured by interaction and cooperation among teachers and students, high efficiency and fast response in writing and feedback. The students who have experienced this new type of training in English writing substantially profit from its real effect. Their analytical abilities in discourse and writing have been improved and raised to the level set by the chief principles of English writing requirements for college students. They can write essays in different styles with rich content, fluent language, appropriate words and expressions. Furthermore, the abilities in self-study and cooperative learning have been enhanced greatly. Writing training under network environment lays special stress on cooperative learning activities in the process of writing after class with the students experiencing one step after another. From the sorrowfully passive writing to the delightfully active writing transformation, the students become confident of their writing abilities, which results in their high-quality writing output. Last but not least, the students' skills in computer and network technology are equally improved. To utilize network resources and develop individual learning habits on the basis of computer and network platform is to meet the demand of network era, and also meet the demand of the Ministry of Education. Therefore, it is an ideal strategy of killing two birds with one stone.

\section{The Existed Problems and Countermeasures}

While in the process of writing practice, we undoubtedly encountered some practical problems to cope with: (1) In view of our technological shortage, the resources of platform cannot be open and beneficial to mostly students, and so we have to optimize our VPIE and Cross-cultural Communication and Policing English Training Platform, combining with other universities and constructing an optimized digital network of good writing resources and training patterns. (2) The interaction in Growing-up QQ Group is unitary. The teacher-to-student and student-to-student interactions aren't sufficient and active. How to fully take advantage of students' writing assignments to realize the goal of online writing directions and multi-dimensional interactions is our primary task at hand. (3) The teachers' workload of writing evaluation on QQ or E-mail system is so heavy that they have to be online working most of their spare time. In order to relieve their work pressure and raise efficiency, we should explore multi-evaluation system, intensifying students' selfevaluation and mutual-evaluation. We also perfect the automated evaluation system and develop comment builder software to make E-system scientific, systematic and reliable.

\section{CONCLUSIONS}

The digital writing platform and other network writing resources provide the teacher with multiple and modern teaching approaches and evaluation means in English writing, and the students with dynamic and optimized writing resources to share and study. Through multimedia classroom teaching, online training and mutual evaluation, the students are more and more actively involved in writing experience and writing interaction. They not only revise and evaluate their own compositions repeatedly, but also fulfill the peer review regularly, offering comments and recommendations. More importantly, this writing strategy reflects and implements the principle of student-centered teaching pattern and achieves the purpose of cooperative learning concept. 80 students as the subjects of this experimental study have obtained, with mixed success, the targeted results, and their valuable learning experiences feed teachers and learners first-hand materials about how to enhance writing abilities in the true sense under the network environment. On-line Writing is the mega trend all over the world, and we can confirm that interactive and cooperative writing strategy predicts a promising prospect.

\section{ACKNOWLEDGMENT}

The author wishes to thank the experts and judges of the Education Department of Liaoning Province for their support of The Foreign Language Reform Project of Liaoning Higher Education Academy of Liaoning Province (2011) No. WYYB110088: On the Network and Field Training of the Cross-cultural Communication Competence in the Higher Vocational Education.

\section{REFERENCES}

[1] Numan, D. (2004).Experience English Teaching. Beijing: Higher Education Press.

[2] LI Zhixue, Li Shaoshan.(2003). Rethinking on the Present State of English Writing Study in China. Foreign Language World, (6):57-62.

[3] Feuerstein, R.P.S. Klein. \& A. J. Tannenbaum.(1991). Mediated Learning Experience: Theoretical Psychological and Learning Implications. London: Freund.

[4] HE Peifen. (2007).Research on Writing Teaching in College English under Network Environment. Journal of Sichuan International Studies University, (2):140-144.

[5] Xi, X.M. (2010). Automated scoring and feedback systems: Where are we and where are we heading? Language Testing, (27):291-300.

[6] Larsen-Freeman, D. (2003).Teaching Language: From Grammar to Grammaring. Boston, MA: Heinle/Cengage.

[7] Murray, S. O. (1994).Theory Groups and the Study of Language in North America. Amsterdam: John Benjamins. 
[8] WEI Li. (2011). Tridimensional Policing English Training under Multimedia and Network Environment. Proceedings of 2011 $3^{\text {rd }}$ International Conference on Signal Processing Systems. IEEE Press, pp.525-528.

[9] WEI Li. (2012). Construction of Seamless English Language Learning Cyberspace via Interactive Text Messaging Tool. Theory and Practice in Language Studies. Vol. 2, No. 8, 1590-1596.

[10] SHI Luoxiang. (2004). A Study on the Interaction of Collaborative Writing in College English Classroom. Journal of Xi'an International Studies University, (2):81-84.

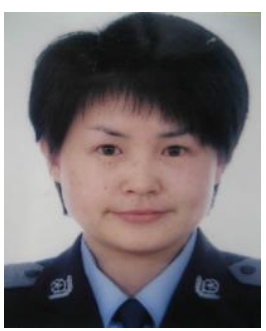

Li Wei: Born in Feb. 1972 in Liaoyang, China. BA of English, Liaoning Normal University, 1993, Master of English, Liaoning Normal University, 2007. She is an associate professor in Liaoning Police Academy; the author of one EI indexed paper and eight international papers. She has published more than 40 papers in Chinese academic journals including World Ethno-national Studies, Shandong Social Sciences, Social Sciences in Xinjiang, Academy. Her concentration centers on the Multicultural education, the Canadian Studies and Foreign Language Teaching with computer and network assistance.

Professor Wei is a candidate for the Police Liaison Officers of the Public Security Ministry of China. 